\title{
Macroscopically oriented (3-pentadecyl phenol) dangled fluorene based conductive polymer through side chain engineering for microelectronics
}

\author{
C. Molji ${ }^{1,3}$, S. Renjith ${ }^{1,2}$, K. B. Jinesh ${ }^{4}$, J. D. Sudha ${ }^{1,3 *}$ \\ ${ }^{1}$ CSIR-National Institute for Interdisciplinary Science and Technology, 695019 Trivandrum, India \\ ${ }^{2}$ Sree Chitra Tirunal Institute for Medical Sciences and Technology, Department of Technology \& Quality Management \\ Central Analytical Facility, BMT Wing, Poojappura, Thiruvananthapuram, Kerala, India \\ ${ }^{3}$ Academy of Scientific and Innovative Research (CSIR-NIIST Campus), India \\ ${ }^{4}$ Department of Physics, Indian Institute of Space Science and Technology, 695547 Thiruvananthapuram, India
}

Received 5 April 2019; accepted in revised form 18 June 2019

\begin{abstract}
In this paper, we have designed a solution processable macroscopically oriented conductive polymer of fluorene dangled 3-pentadecylphenol (Polyfluorene pentadecyl benzene, PFLPDB) through side chain engineering and self-assembly approach. Initially fluorene was coupled with 3-pentadecylphenol (3-PDP) and further subjected to oxidative polymerisation in the presence of anhydrous ferric chloride $\left(\mathrm{FeCl}_{3}\right)$. Effects of polarity of the solvent and time on self-assembly process was studied using various microscopic techniques which suggested the formation of macroscopically oriented fibers having 20-30 nanometer diameter in chloroform with an electrical conductivity of $\left(2.1 \cdot 10^{-2} \mathrm{~S} \cdot \mathrm{cm}^{-1}\right)$. Optical and electrochemical band gaps were calculated from the studies made by UV-Vis spectroscopy and cyclic voltammetry. Its field effect transfer characteristics were further studied by fabricating an Organic field effect transistor (OFET) device having configuration $\left(\mathrm{Si} / \mathrm{SiO}_{2} / \mathrm{PFLPDB} / \mathrm{Ag}\right)$ and measured its field effect mobility $\left(1.076 \mathrm{~cm}^{2} \cdot \mathrm{v}^{-1} \cdot \mathrm{s}^{-1}\right)$ at $1 \mathrm{~V}$ and ON/OFF ratio of the device calculated as $1.82 \cdot 10^{3}$ suggests its application as an excellent active material for organic microelectronics.
\end{abstract}

Keywords: polymer synthesis, molecular engineering, macroscopically ordered, 3-pentadecyl phenol dangled fluorene, OFET

\section{Introduction}

Design and development of processable macroscopically ordered intrinsically conducting polymers (ICPs) are receiving overwhelming interest in the academia and industry owing to the emergence of versatile flexible microelectronic devices such as energy storage, photovoltaics, organic field effect transistors (OFET), organic light emitting diodes (OLED), display technology and bio-medical applications [1-5]. These flexible, portable and implantable electronic devices became globally as one of an inevitable constituents in our everyday life [6-8]. ICPs are endowed with unique opto-electronic properties, excellent thermo-mechanical stability, low band gap, excellent charge carrier mobility, solution processability, flexibility, light weight, portable in nature compared to their inorganic counterparts [9-11]. Among these solution processability is one of the most attractive features of organic semiconductors, enabling low-cost, low-temperature, and large-area device fabrication $[12,13]$.

A solution processable conjugated polymer generally contains two parts, $\pi$-conjugated polymer backbone and peripheral solubilizing side chains. The $\pi$-conjugated backbone determines the optical, electrochemical and electronic behaviour of that material 
[14]. Whereas side chains enhance the processability and the formation of ordered films [15]. Recent studies showed that side chain engineering can also tune the physical properties of polymer including absorption, emission, energy levels, molecular packing, and charge transport [16-18]. Thus charge carrier mobilities are highly dependent on the molecular orientation and crystal grain size, which in turn depend on the chemical structures, interchain packing of the $\pi$ conjugated backbones and the deposition parameters [19]. In particular, the design and development of a large range of different conjugated polymers, focused on improving the optical absorption, planarizing the aromatic backbone, and therefore adjusting the molecular orbital energy levels, has led to an improved understanding of the structure properties relationships [14, 20, 21].

Several groups recently reported the new design of alkyl side chains to strike a good balance between polymer solubility and main chain packing. Most of the highest performing polymers show short $\pi$-stacking distances between polymer backbones with wave functions often widely delocalized over the polymer conjugated aromatic system [22, 23]. These properties, leading to high charge carrier mobilities and can be used as active materials in organic field effect transistors [24-27]. Recently Wang et al. [28] reported a diketopyrrolopyrrole (DPP) based semiconducting polymers with phytol derived alkyl side chains which showed good solubility in most of the organic solvents and had longer effective conjugation length compared to the DPP polymer with conventional branched side chains. In another report Huang et al. [29] studied the semiconducting properties and side chain self-assembly of Heptacyclic Anthradithiophene Diimide polymer. They accomplished that the backbone geometry and side-chain self-assembly are key factors that govern the aggregation of conjugated semiconducting polymers and affect charge transport.

An alkyl substituted fluorene moiety represents a very favourable building block for obtaining processable, conjugated polymers and its excellent optical and electrical properties makes semiconducting poly (fluorene)s and their analogues as an active material in organic electronic devices [12, 20]. In 1989 Fukuda et al. [30] first synthesised soluble poly (2,7-fluorene)s via ferric chloride oxidative polymerization. Thereafter synthesis of fluorene based conjugated polymers accelerated due to their high chemical and thermal stability. Literature review shows that alkyl fluorene shows excellent photo physical and electronic properties which varies with sidechain engineering. Islam et al. [31] designed highly soluble and emissive fluorene and thiophene based copolymers and studied its electroluminescent properties by varying side chain substitution. In another report Tseng et al. [32] studied the reason for high charge carrier mobility of fluorene and benzothiadiazole copolymer and fabricated OFET device by drop casting the semiconducting polymer.

In the present work, alkyl substituted fluorene is designed by coupling with 3-pentadecylphenol (3PDP). 3-PDP is a distillation product of the cashew nut shell (CNSL) which is obtained as an industrial by-product from cashew industry and is abundantly available low cost alkyl phenol having unique structure of $\mathrm{C}_{15}$ long flexible alkyl chain [33-35].Commonly, the C-9 position in the fluorene rings is modified to improve the processability and photo stability of polyfluorenes. Due to the tetrahedral $\sigma$-bonding at the C-9 atom, the substituents tend to extend out of the backbone plane and be locally perpendicular to the chain-axis $[36,37]$. Therefore, 3-PDP substitution at the C-9 position does not greatly increase the steric interactions [38-40]. Moreover the long flexible alkyl chains can enhance the self-assembly process through electrostatic layer by layer assembling (ELBLS) and the backbone can contribute through $\pi-\pi$ stacking and hydrogen bonding. Among the various routes to orient and self-assemble the polymer chains, solvent-induced ordering; either by solvent vapour annealing or by pre-aggregation in solutions, is the simplest method which can reduce the cost and avoid the requirements of specially prepatterned substrates for plastic electronic devices $[25,41]$. Precise selection of polarity of the solvents can control the pre-aggregation of polymer chains in solutions which will invariably control their self-assembly to generate macroscopically oriented fibers when cast on substrates [42, 43]. Here we studied the self-assembly of these polymer with solvent polarity and it was monitored by observation under various microscopic techniques and further the formed oriented fibers were used as an active material for the fabrication of OFET $\left(\mathrm{Si} / \mathrm{SiO}_{2} / \mathrm{PFLPDB} / \mathrm{Ag}\right)$ and studied its transistor performance. 


\section{Experimental}

\subsection{Materials}

Fluorene (97\%), and 1,4-dibromobutane were purchased from sigma Aldrich India, 3-pentadecyl phenol prepared by the hydrogenation of cardanol (3pentadecenyl phenol) as reported earlier [33]. Potassium hydroxide, anhydrous ferric chloride of analytical quality were supplied by Merck India. All solvents were of analytical grade and used as such. Air and water sensitive synthetic steps were performed in an argon atmosphere.

\subsection{Characterization}

${ }^{1} \mathrm{H}$ MR proton nuclear magnetic resonance spectra were measured on a $500 \mathrm{MHz}$ Bruker Advance DRX600 Spectrometer. All the chemical shifts were referenced to $\left(\mathrm{CH}_{3}\right)_{4} \mathrm{Si}$ (TMS; $\delta=0 \mathrm{ppm}$ ) for ${ }^{1} \mathrm{H}$. Molecular mass was confirmed with JEOL JM AX 505 HA Mass spectrometer performing Fast atom bombardment for producing molecular ions. Electronic absorption spectra were recorded on a Shimadzu UV-2100 spectrophotometer using quartz cuvettes with $1 \mathrm{~cm}$ path length. Thermal stability measurements were performed at a heating rate of $10^{\circ} \mathrm{C} / \mathrm{min}$ in nitrogen atmosphere using Shimadzu DTG 60 equipment. Alumina pans were used for the measurement and as reference samples. The analysis was conducted between 50 and $90^{\circ} \mathrm{C}$ at $10^{\circ} \mathrm{C} \cdot \mathrm{min}^{-1}$ under dry $\mathrm{N}_{2}$. Fourier transform infrared FT-IR spectroscopic measurements were made with a fully computerized Nicolet Impact 400D FT-IR spectrophotometer. IR spectra were recorded in the range of 4000 to $500 \mathrm{~cm}^{-1}$. All spectra were corrected for the presence of moisture and carbon dioxide in the optical path. The experiments were performed for a scan of 45 times and with a resolution of $4 \mathrm{~cm}^{-1}$. Molecular weight of PFLPDB was obtained by Gel Permeation Chromatography using Waters (GPC-Waters515 HPLC pump, Styragel THF column and Waters 717 auto injector) using polystyrene standard. Clear solution of sample is prepared in THF $(1 \mathrm{mg} / 10 \mathrm{ml})$. Cyclic voltammetry studies were carried out using a CHI6211B electrochemical analyser in a three-electrode/one-compartment electrochemical cell in which glassy carbon electrode (GCE) was used as working electrode and a platinum wire was used as counter electrode. All of the potentials were recorded using $\mathrm{Ag} / \mathrm{AgCl}$ as the reference electrode. Four-probe conductivity meter was used for electrical conductivity measurements, which consist of a Keithley 6221 programmable current source and a 2128A Nano voltmeter. Pelletised samples having diameter of $14 \mathrm{~mm}$ and thickness of $1.5 \mathrm{~mm}$ was used for measuring the conductivity. Solvent induced morphological variation of PFLPDB was observed using various microscopic techniques such as scanning electron microscopy, SEM, transmission electron microscopy TEM and atomic force microscopy, AFM. SEM observations of samples were performed by subjecting the samples for a thin gold coating using a JEOL JFC-1200 fine coater. The probing side was inserted into JEOL JSM-5600 LV scanning electron microscope for imaging. For TEM measurements, the samples were casted on a carbon-coated copper grid and dried in vacuum at room temperature before observation. Samples for the analysis were prepared by drop casting the polymer solution on a glass slide. Atomic force microscopic images were made under ambient conditions using a Bruker Multimode AFM$3 \mathrm{COCF}$ (Germany) operating in tapping mode. Micro fabricated silicon cantilever tips (MPP-11100-10) with a resonance frequency of $284-299 \mathrm{kHz}$ and a spring constant of $20-80 \mathrm{~N} \cdot \mathrm{m}^{-1}$ were used. The scan rate varied from 0.5 to $1.5 \mathrm{~Hz}$. Self-assembly process for the formation of macroscopically oriented fibers of the cast films was analyzed with X-ray diffraction (XRD) (Wide angle X-ray scattering WAXS and small angle X-ray scattering SAXS) analyses conducted on a XEUSS 2D SAXS/WAXS system using a Genix micro source from Xenocs operated at $50 \mathrm{kV}$ and $0.3 \mathrm{~mA}$. The $\mathrm{Cu}-\mathrm{K} \alpha$ radiation $(\lambda=1.54 \AA)$ was collimated with a FOX2D mirror and two pairs of scatter less slits from Xenocs. For fabricating thin film transistors polymer active layer were casted on $60 \mathrm{~nm}$ thick $\mathrm{SiO}_{2}$ coated Si substrate using a Holmarc spin coater (model: HO-TH-05) at a rate of $1000 \mathrm{rpm}$. The transistor characteristics were obtained using Cascade four-probe station connected to Agilent B1500A semiconductor parameter analyser.

\subsection{Preparation of polyfluorene pentadecyl benzene (PFLPDB)}

Polymer PFLPDB was prepared by a two step reaction process. Initially we prepared the side chain substituent bromobutoxy pentadecyl benzene (BBPDB) by the functinalisation of $\mathrm{OH}$ group of 3-pentadecyl phenol (3-PDP). Then alkylation of fluorene with BBPDB to form fluorene pentadecyl benzene (FLPDB). Finally polymerisation of FLPDB to PFLPDB. 


\subsubsection{Synthesis of FLPDB}

$4 \mathrm{~g}$ (0.009 mol) 3-pentadecylphenol and $20 \mathrm{ml} \mathrm{1,4-}$ dibromobutane were stirred for 30 minutes in a two neck RB flask. Later $1.5 \mathrm{~g}(0.01 \mathrm{~mol})$ of $\mathrm{K}_{2} \mathrm{CO}_{3}$ was added and refuxed for $6 \mathrm{hrs}$. Progress of the reaction was monitored by conducting TLC of reaction mixture. After completion of reaction, the reaction was filtered through a whatmann No 41 filter paper.Then the compound was purified by column chromatography using hexane as eluent and the purified product is designated as BBPDB (1-(4-bromobutoxy)-3-pentadecyl benzene). Pale yellow liquid; yield $90 \%$; ${ }^{1} \mathrm{H} \mathrm{NMR}\left(\mathrm{CDCl}_{3}\right)(\delta=7.16 \mathrm{ppm})(1 \mathrm{H}, \mathrm{d}), 6.76(1 \mathrm{H}$, s), $6.70(2 \mathrm{H}, \mathrm{q}), 3.97(2 \mathrm{H}, \mathrm{t}), 3.48(2 \mathrm{H}, \mathrm{t}), 2.56(2 \mathrm{H}$, t), $2.02(2 \mathrm{H}, \mathrm{q}), 1.93(2 \mathrm{H}, \mathrm{q}), 1.58(2 \mathrm{H}, \mathrm{m}), 1.29(6 \mathrm{H}$, m), $0.87(3 \mathrm{H}, \mathrm{t})$. HRMS (ESI) $m / z:[\mathrm{M}+]+$ calcd for $\mathrm{C}_{25} \mathrm{H}_{43} \mathrm{OBr}$, 439.51; found, 438.36 .

Later fluorene $(1.009 \mathrm{~g}, 0.006 \mathrm{mmol})$ was mixed with BBPDB $(5.27 \mathrm{~g}, 0.012 \mathrm{mmol})$ in a two phase system composed of toluene $(20 \mathrm{ml})$ and $\mathrm{NaOH}(50 \% \mathrm{w} / \mathrm{w}$ aqueous solution). Tetra butyl ammonium bromide $(0.3 \mathrm{~g}, 0.9 \mathrm{mmol})$ used as the phase transfer catalyst and heated at $60^{\circ} \mathrm{C}$ for $4 \mathrm{hrs}$. After diluting the reaction mixture with ethyl acetate, the organic layer was washed with water. The separated organic layer was dried over magnesium sulphate and the solvent was evaporated off. Extent of reaction was monitored using thin layer chromatography (TLC) which showed one major spot corresponding to the mono alkylated (FLPDB) and a small spot of dialkylated product (DFLPDB) and from this mixture of products FLPDB was purified by column chromatography using $\mathrm{CHCl}_{3}$ as eluent. FLPDB was then recrystallized from ethanol to give yellow orange tinged crystals and used for further polymerisation reaction. Yield: yellow orange tinged crystals (74\%), mp: $72{ }^{\circ} \mathrm{C}$, HRMS (ESI) $\mathrm{m} / \mathrm{z}$ : $[\mathrm{M}+]+$ calcd for M.F $\mathrm{C}_{38} \mathrm{H}_{52} \mathrm{O}$ 523.32, Found 523.09; Elemental analysis; clcd C $86.96 \%$, H 9.99\%, O 3.05\%; Found C 85.10\%, $\mathrm{H} 9.32 \%, \mathrm{O} 2.71 \%{ }^{1} \mathrm{H}$ NMR $\left(\mathrm{CDCl}_{3}\right)(\delta=7.80 \mathrm{ppm})$ $(\mathrm{d}, 4 \mathrm{H}, J=5.4 \mathrm{~Hz}), 7.68(\mathrm{~s}, 1 \mathrm{H}), 7.5(\mathrm{~d}, 4 \mathrm{H}, J=$ $5.4 \mathrm{~Hz}), 4.1(\mathrm{t}, 2 \mathrm{H}, J=6.2 \mathrm{~Hz}), 3.82(\mathrm{~s}, 1 \mathrm{H}, J=$ $7.8 \mathrm{~Hz}), 1.63-1.68(\mathrm{~m}, 4 \mathrm{H}), 1.22-1.35(\mathrm{~m}, 10 \mathrm{H})$, $0.87(\mathrm{t}, 3 \mathrm{H}, J=7 \mathrm{~Hz})$.

\subsubsection{Polymerisation of FLPDB (1-pentadecyl-3-(pentyloxy) benzene-9H-fluorene}

Polymerisation of FLPDB was carried out in chloroform using $\mathrm{FeCl}_{3}$ as oxidative initiator. Initially $1 \mathrm{~g}(0.0019 \mathrm{~mol})$ FLPDB was dissolved in $50 \mathrm{ml}$ $\mathrm{CHCl}_{3}$ stirred for until complete dissolution. Then $0.5 \mathrm{~g} \mathrm{FeCl}_{3}(0.003 \mathrm{~mol})$ was added and magnetically stirred 48 hrs under ice-cold condition. Finally, the product was precipitated using ethanol. Then the product washed several times with ethanol. After that product extracted with chloroform-water mixture and dried and named as PFLPDB. Finally analysed by NMR. Yield 82\%; Molecular mass was calculated by GPC and found that $79519 \mathrm{Da}$ as given in Table 1. Elemental analysis; calcd. C 86.61\%, H 10.44\%, O $2.96 \%$; Found C $86.56 \%$, H $10.63 \%$, O 2.81 ${ }^{1} \mathrm{H} \mathrm{NMR}\left(\mathrm{CDCl}_{3}\right)(\delta=7.80 \mathrm{ppm}(\mathrm{d}, 4 \mathrm{H}, J=5.4 \mathrm{~Hz})$, $7.68(\mathrm{~s}, 1 \mathrm{H}), 7.5(\mathrm{~d}, 4 \mathrm{H}, J=5.4 \mathrm{~Hz}), 4.1(\mathrm{t}, 2 \mathrm{H}, J=$ $6.2 \mathrm{~Hz}), 3.82(\mathrm{~s}, 1 \mathrm{H}, J=7.8 \mathrm{~Hz}), 1.63-1.68(\mathrm{~m}, 4 \mathrm{H})$, $1.22-1.35(\mathrm{~m}, 10 \mathrm{H}), 0.87(\mathrm{t}, 3 \mathrm{H}, J=7 \mathrm{~Hz})$.

\subsection{OFET fabrication}

To evaluate the performance of PFLPDB as an active material for the electronic device fabrication, bottom gate thin film transistor was built with $\mathrm{Si} / \mathrm{SiO}_{2} /$ PFLPDB/Ag configuration. The primary purpose of the OFET experiments was to show the potential of the PFLPDB material as a semiconductor. PFLDB ( $1 \%$ PFLPDB in chloroform) was coated on the $\mathrm{Si} / \mathrm{SiO}_{2}$ substrate to get a uniform film at $1200 \mathrm{rpm}$. After spin coating, the film was annealed for $30 \mathrm{~min}-$ utes at $80^{\circ} \mathrm{C}$ for the complete evaporation of solvents. Then, silver electrodes were thermally evaporated onto the films, using a shadow mask to form the source and drain with a Fillunger vacuum deposition system. The channel length and width of the fabricated TFT was $160 \mu \mathrm{m}$ and $0.5 \mathrm{~mm}$ respectively.

\section{Results and discussion}

Polyfluorene substituted with 3-pentadecyl phenol (PFLPDB) was prepared by a two step process involving coupling of BBPDB with fluorene followed by oxidative polymerisation using ferric chloride.

Table 1. GPC data of PFLPDB.

\begin{tabular}{|c|c|c|c|c|c|c|}
\hline $\boldsymbol{M}_{\mathbf{n}}$ & $\boldsymbol{M}_{\mathbf{w}}$ & $\boldsymbol{M}_{\mathbf{p}}$ & $\boldsymbol{M}_{\mathbf{Z}}$ & $\boldsymbol{M}_{\mathbf{z}+1}$ & $\boldsymbol{M}_{\mathbf{v}}$ & Polydispersity \\
\hline 231056 & 280309 & 79519 & 1864943 & 3131429 & & 1.21316 \\
\hline
\end{tabular}




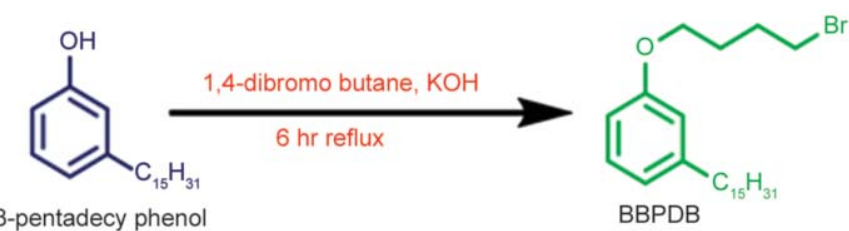

a)

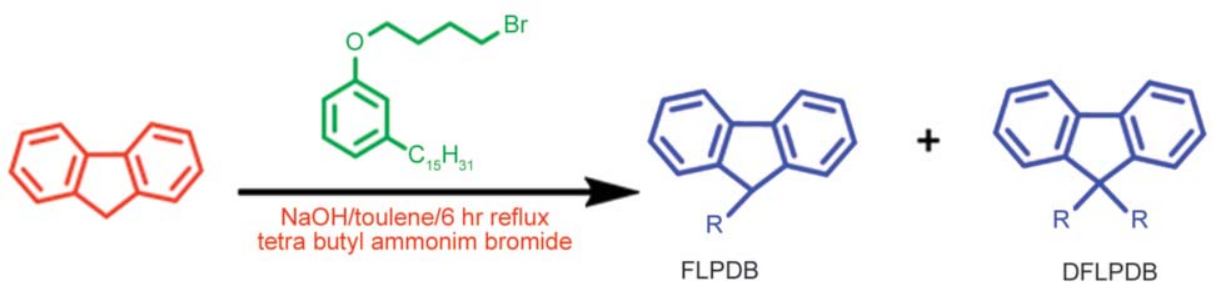

b)

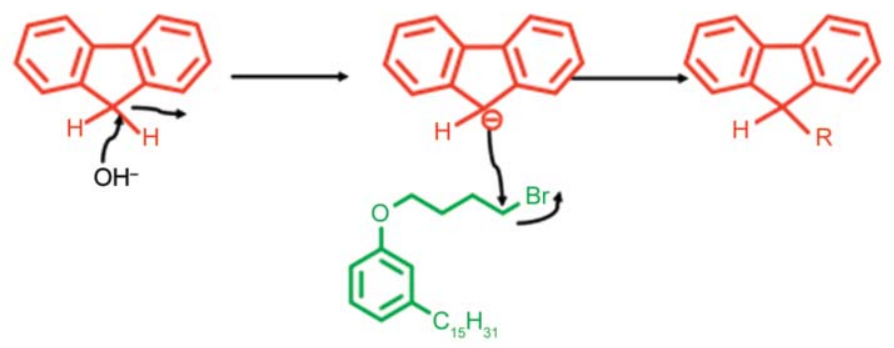

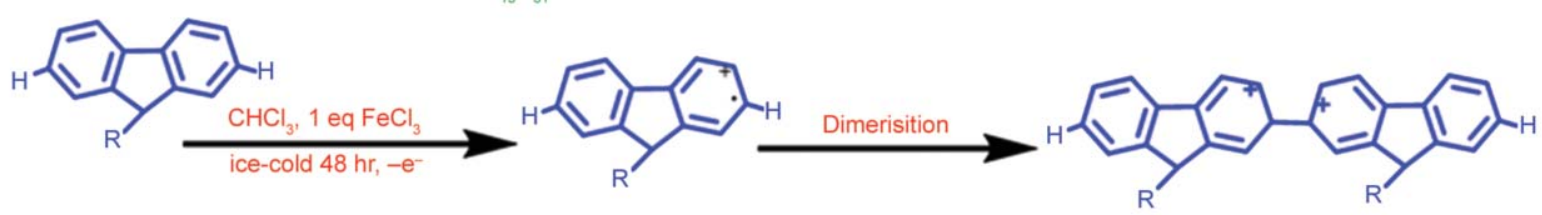

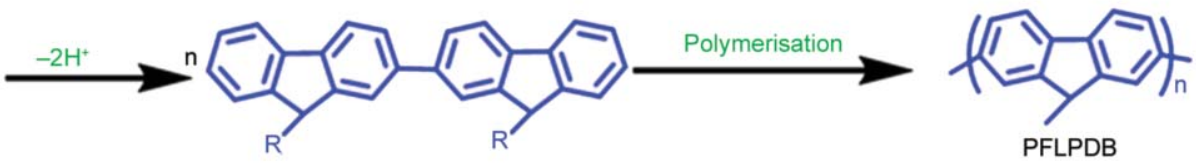

c)

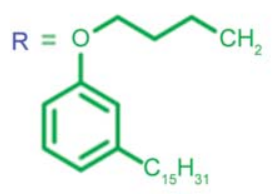

Figure 1. Synthesis of a) BBPDB, b) FLPDB, c) PFLPDB.

The schematic representation for the formation of PFLPDB is shown in Figure 1. Initial step of coupling reaction includes functionalisation of the hydroxyl group in 3-PDP using 1,4-dibromobutane to form BBPDB. Then bromoalkylated compound, BBPDB was treated with fluorene, where a new $\mathrm{C}-\mathrm{C}$ bond is expected to form on the $9^{\text {th }}$ position of fluorene since the $\mathrm{H}$ is acidic in nature. The mechanism of alkylation depicted in Figure 1. Initially hydroxyl anion abstract poton from the $9^{\text {th }}$ position of fluorene. Thus the carbanion formed was resonance stabilised and it undergoes nucleophilic attack on the alkyl bromide (Bromobutoxypentadecyl benzene, BBPDB) forms the BBPDB substituted fluorene designated as FLPDB. Here, the substitution leads to two products such as monoalkyated and dialkylated fluorene which was intially monitored by thin layer chroatography
(TLC). For reducing the steric hindrance, we have optimised the condition for the monoalkyl derivative. Monoalkyl derivative is expected to form more expanded conformation sothat the charges can transport without any hindrance [14]. Further monosubstituted fluorene (FLPDB) was separated and purified by column chromatography using chloroform as the eluent. Yield: $74 \%$.

Formation of the monosubstituted FLPDB was confirmed by melting point $\left(72^{\circ} \mathrm{C}\right)$, elemental analysis, NMR and by FTIR and the results are given in the experimental section. In ${ }^{1} \mathrm{H}$ NMR of FLPDB (Figure 2) The sharp signal $\delta\left([\mathrm{ppm}], \mathrm{CDCl}_{3}\right)$ at $3.82 \mathrm{ppm}$ corresponds to benzylic proton at the $9^{\text {th }}$ position of fluorene indicate the monoalkylation of one of the bridge protons. The triplet at $4.1 \mathrm{ppm}$ comes from a $\mathrm{CH}_{2}$ proton near to an oxygen atom indicated the 


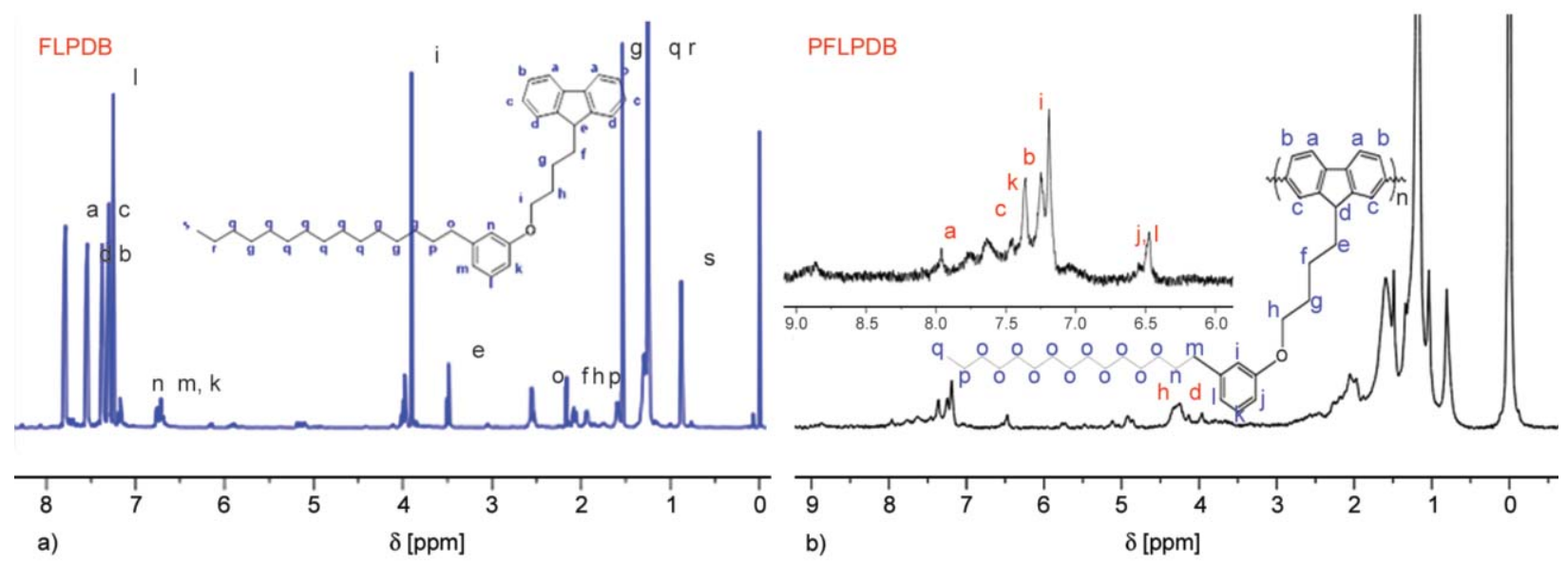

Figure 2. a) ${ }^{1} \mathrm{H}$ NMR spectrum of FLPDB, b) ${ }^{1} \mathrm{H}$ NMR spectrum of PFLPDB.

presence of 3-PDP moiety, which further confirmed the coupling of 3-PDP with fluorene. Further polymerization of FLPDB was carried out using $\mathrm{FeCl}_{3}$ as the oxidative initiator for $48 \mathrm{hrs}$ under ice-cold condition [44-48]. Product was precipitated in ethanol and repeatedly centrifuged and washed with alcohol. Finally the PFLPDB residue was again dissolved in chloroform and extracted with $\mathrm{CHCl}_{3}$-water mixture for removing all the byproducts and unreacted $\mathrm{FeCl}_{3}$.
${ }^{13} \mathrm{C}$ NMR spectrum of FLPDB is given in Figure 3. The peaks observed at 114 to $150 \mathrm{ppm}$ corresponding to the aromatic carbon present in the 3-PDP and fluorene moiety. The sharp single peak at 159 ppm corresponding to the aryl carbon near to the oxygen atom in the 3-PDP again confirmed the coupling of 3-PDP with fluorine entity. The characteristic peak for $\mathrm{O}-\mathrm{CH} 2$ carbon in the side chain substituent observed at $70 \mathrm{ppm}$.

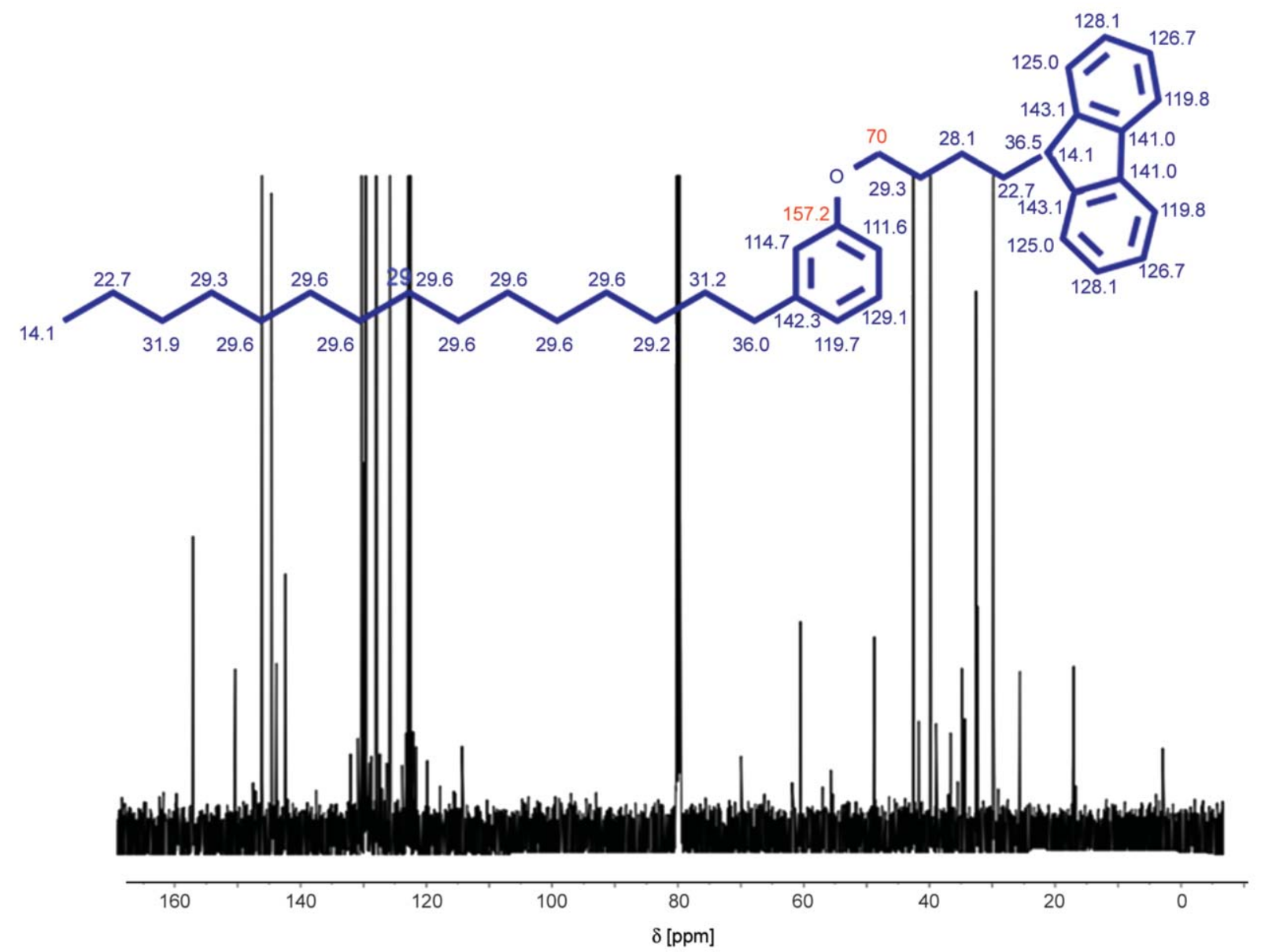

Figure 3. ${ }^{13} \mathrm{C}$ NMR spectrum of FLPDB. 


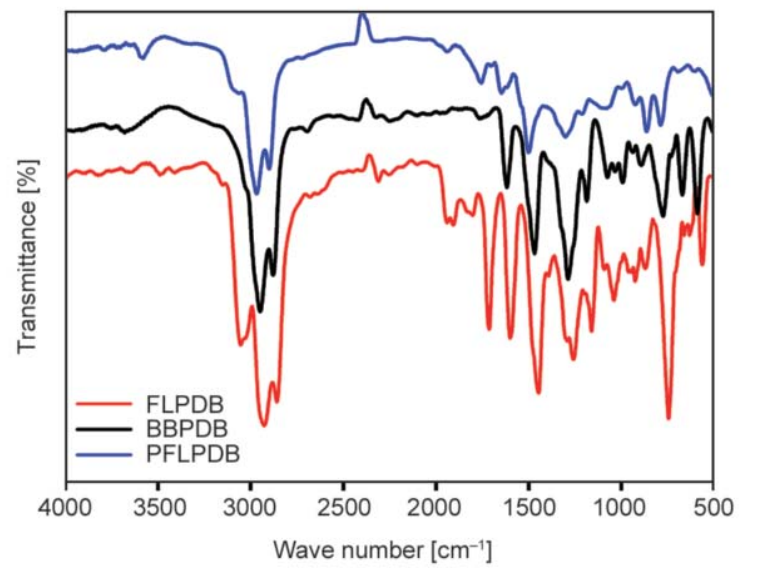

Figure 4. FTIR spectrum of Fluorene, FLPDB and PFLPDB.

FTIR spectra of BBPDB, FLPDB and PFLPDB are shown Figure 4. In literatures characteristic band observed for fluorene are $2900-3000 \mathrm{~cm}^{-1}, 1455$ $1650 \mathrm{~cm}^{-1}$, corresponding to symmetric and asymmetric $\mathrm{C}-\mathrm{H}$ stretching vibrations, aromatic $\mathrm{C}=\mathrm{C}$ stretching vibration respectively. BBPDB shows bands at $2860-3000 \mathrm{~cm}^{-1}$ (aromatic and aliphatic $\mathrm{C}-\mathrm{H}$ stretching vibration), $1475-1600 \mathrm{~cm}^{-1}$ (aromatic skeletal vibrations), $1250-1050 \mathrm{~cm}^{-1}$ (C-O-C stretching), $669 \mathrm{~cm}^{-1}$ (C-Br stretching). FLPDB exhibited combination of both these bands in the IR spectrum confirmed the coupling of fluorene with BBPDB. IR spectrum of the polymer also revealed the presence aromatic and aliphatic moiety. The characteristic bands of PFLPDB observed at $2850,3000 \mathrm{~cm}^{-1}$ represent aromatic $\mathrm{C}-\mathrm{H}$ stretching and the bands measured at 1450, 1560, $1690 \mathrm{~cm}^{-1}$ attributes for the skeletal vibrations of aromatic rings confirmed structure of PFLPDB. It has been observed that the characteristic bands in the FLPDB were shifted and broadened in

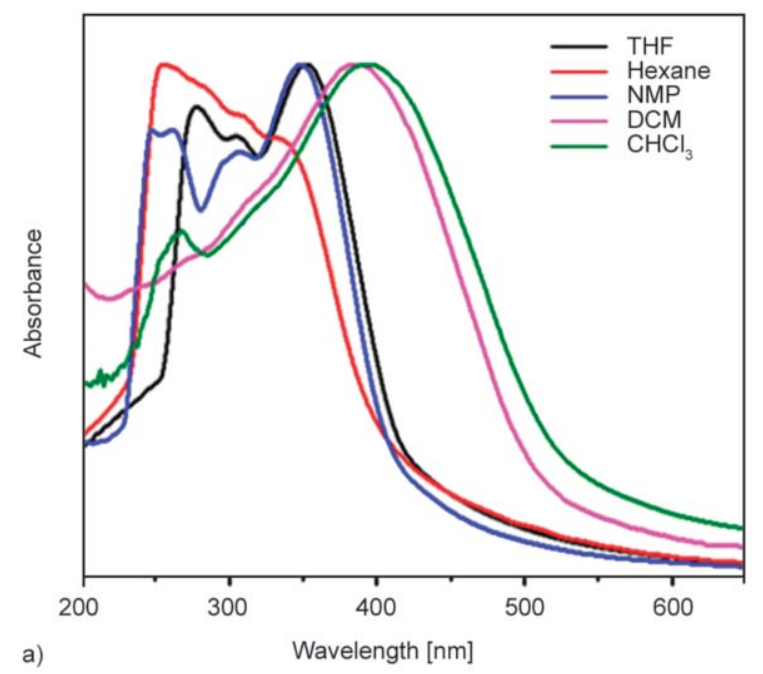

PFLPDB due to the various extents of interchain interactions such as $\pi-\pi$ interaction, electrostatic layer by layer assembling (Figure 8) present in PFLPDB. The bilayer formation and the self-assembly process among the PFLPDB molecular chains are further discussed in more detail below.

\subsection{Self-assembly proces of PFLPDB}

Effect of polarity of the solvent and time on the selfassembly process of PFLPDB was studied using various microscopic techniques, UV-Vis spectroscopy and cyclic voltammetry. Optical and electrochemical properties of PFLPDB in solvents such as chloroform $\left(\mathrm{CHCl}_{3}\right)$, tetrahydrofuran (THF), $\mathrm{N}$-methyl-2pyrrolidone (NMP), dichloromethane (DCM) and hexane was studied and is shown in Figure 5. UVVis spectroscopic studies in various solvents revealed the solvatochromic effect and it exhibited red shift when changing the solvent from hexane to NMP to THF to DCM to chloroform. In hexane the absorption band observed as a broad band maxima at 280-250 nm. In THF and NMP, the first band retains almost in the same wavelength whereas the second band is shifted to $380 \mathrm{~nm}$. In chloroform and DCM, the band are overlapped and shifted to $430 \mathrm{~nm}$. The band observed at $250-280 \mathrm{~nm}$ is attributed to the $\pi-\pi^{*}$ transition of the benzenoid structure. The band at $350 \mathrm{~nm}$ corresponds to a polaron interband transition. Optical band gap was calculated from the Tauc plot obtained from the corresponding reflectance spectra using the Tauc's relation (Equation (1)):

$(\propto h \vartheta)^{\frac{1}{n}}=\beta\left(h \vartheta-E_{\mathrm{g}}\right)$

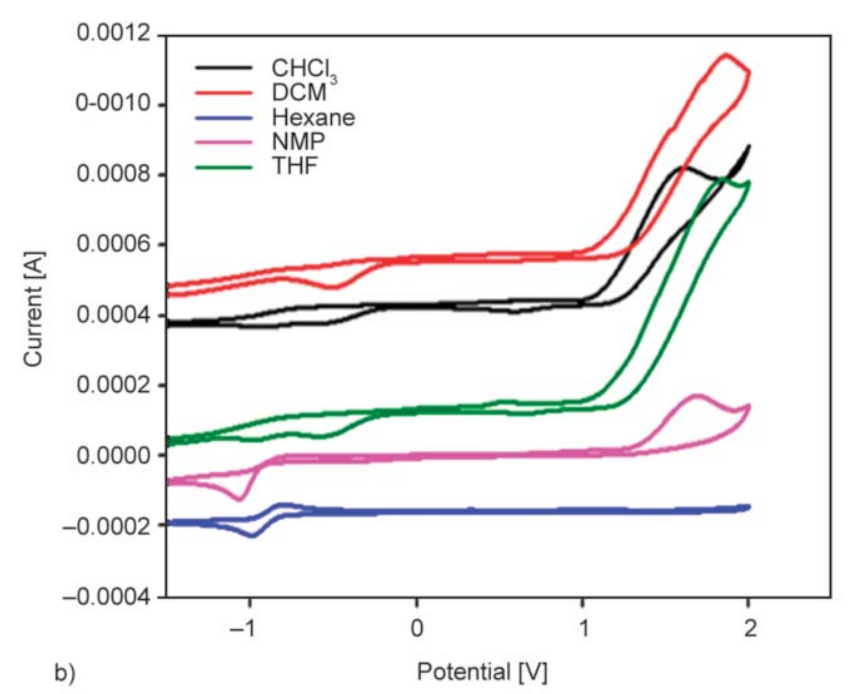

Figure 5. a) UV-Visible spectra and (b) cyclic voltammogram of PFLPDB in $\mathrm{CHCl}_{3}$, THF, NMP, DCM, and hexane. 
where $\beta$ is a constant called the band tailing parameter, $E_{\mathrm{g}}$ is the energy of the optical band gap and $n$ is the power factor of the transition mode, which is dependent upon the nature of the material, whether it is crystalline or amorphous. Optical band gap of PFLPDB for $\left(\mathrm{CHCl}_{3}-2.28 \mathrm{eV}, \mathrm{DCM}-3.22 \mathrm{eV}\right.$, hexane $-3.03 \mathrm{eV}, \mathrm{THF}-2,9 \mathrm{eV}$ and NMP $-2.95 \mathrm{eV}$.) These observed red shift in DCM and $\mathrm{CHCl}_{3}$ can be explained due to formation of self-assembled extended chains of PFLPDB which facilitated the inter chain charge hopping of the charge carriers and enhancement in conductivity and reduction in the optical band gap [39]. Electrochemical properties were studied using the cyclic voltammetry and Figure $5 \mathrm{~b}$ shows the electrochemical process observed for PFLPDB casted using the above solvents. Then the electrochemical band gap calculated from the Equation (2) and (3) using oxidation and reduction potential observed during the electrochemical process. Electrochemical and optical band gaps are given in Table 2. Electrochemical band observed for $\left(\mathrm{CHCl}_{3}\right.$ $-2.03 \mathrm{eV}, \mathrm{DCM}-2.35 \mathrm{eV}$, hexane $-2.04 \mathrm{eV}$, THF $-2.17 \mathrm{eV}$ and NMP $-2.74 \mathrm{eV}$.

$$
\begin{aligned}
& \mathrm{HOMO}=-\left(E_{\text {onset }}^{\mathrm{ox}}+4.4\right) \mathrm{eV}=5.6 \mathrm{eV} \\
& \mathrm{LUMO}=-\left(E_{\text {onset }}^{\mathrm{re}}+4.4\right) \mathrm{eV}=3.8 \mathrm{eV}
\end{aligned}
$$

Solid state absorption spectra of PFLPDB shown in Figure 6. In solid state the optical band gap calculated by Tauc relation was $1.7 \mathrm{eV}$, suggesting the semiconducting nature of the prepared polymer PFLPDB. By comparing the details of the band gap calculated by optical and electrochemical method it is clear that polymer showed lowest band gap in PFLPDB films casted from $\mathrm{CHCl}_{3}$. Theoretically the band gap of PFLPDB calculated using computational method as shown in Figure 7. By B3LYP/3-21 g and the HOMO/ LUMO energies calculated as are $-5.28 /-1.45 \mathrm{eV}$ with energy gaps of $3.82 \mathrm{eV}$.

Further self-assembly process was studied using various microscopic techniques such as SEM, TEM and AFM. Time dependent self-assembly process in chloroform was studied and the observed morphological changes are shown in Figure 8. Initially PFLPDB

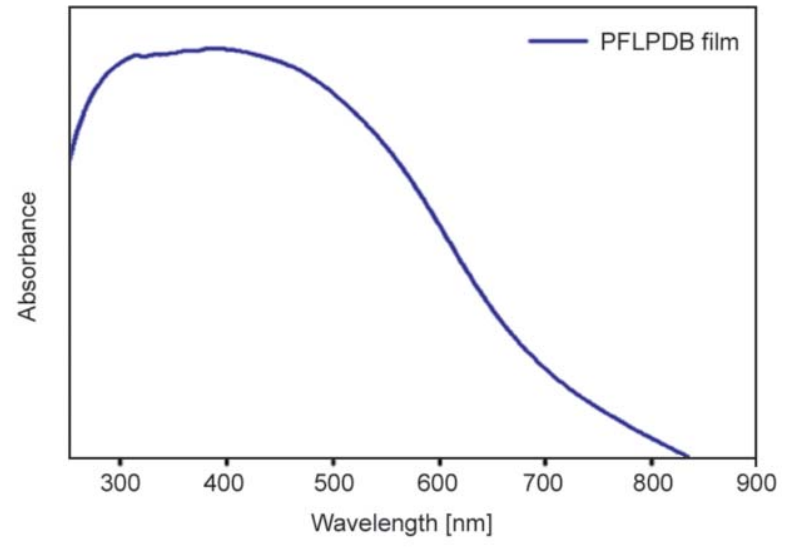

Figure 6. UV-Visible spectra of PFLPDB film formed from $\mathrm{CHCl}_{3}$

self-assembled to form spherical micelle through bilayer formed by $\pi-\pi$ interaction of the aromatic rings and also through electrostatic layer by layer assembling of long alkyl chains (Figure 9a and 9b). Further they aggregate to form two dimensionally ordered focal conical structures and corresponding microscopic SEM images are shown in Figure $9 \mathrm{~d}$ and $9 \mathrm{~g}$. As time lapses to $4 \mathrm{hrs}$, these focal conical structures alternately arranges to form spike like structures (Figure 9e). Later after $8 \mathrm{hrs}$, these structures again attains more ordered arrange to form macroscopically oriented fibers with nanometer diameter (Figure $9 \mathrm{f}$ and 9h).The microscopic pictures of a PFLPDB aggregation in THF showing aggregated petals are shown in (Figure 9i). This supports the observed reduced optical electrochemical and optical band gap and the excellent electrical conductivity observed for films casted from chloroform and it can contribute for the necessary pathway for the charge carriers which has a major impact on the device performance.

Further self- assembly process and the dimension of the aggregated macroscopic fibres observed from $\mathrm{XRD}$. XRD diagram of PFLPDB is given inside the Figure 8.It showed a broad halo around $2 \theta=20.64^{\circ}$ with a $d$-spacing of $4.4 \AA$ correspond to interlayer distance between the molecular chains. In addition, a relatively narrow sharp peak was observed at $2 \theta=$ $3.21^{\circ}$ with a $d$-spacing of $27 \AA$, which corresponds to the intra-columnar distance between the cores in the hexagonal lattice. A strong narrow peak observed at $2 \theta=1.21^{\circ}$ with a $d$-spacing of $51.36 \AA$ correspond

Table 2. Optical and electrochemical band gap of PFLPDB in 5 different solvent.

\begin{tabular}{|l|c|c|c|c|c|c|c|}
\hline \multicolumn{2}{|c|}{ Band gap } & $\mathbf{C H C l}_{\mathbf{3}}$ & DCM & Hexane & NMP & THF \\
\hline Optical bandgap & {$[\mathrm{eV}]$} & 2.28 & 3.22 & 3.03 & 2.93 & 2.95 \\
\hline Electrochemical band gap & {$[\mathrm{eV}]$} & 2.03 & 2.35 & 2.04 & 2.74 & 2.17 \\
\hline
\end{tabular}



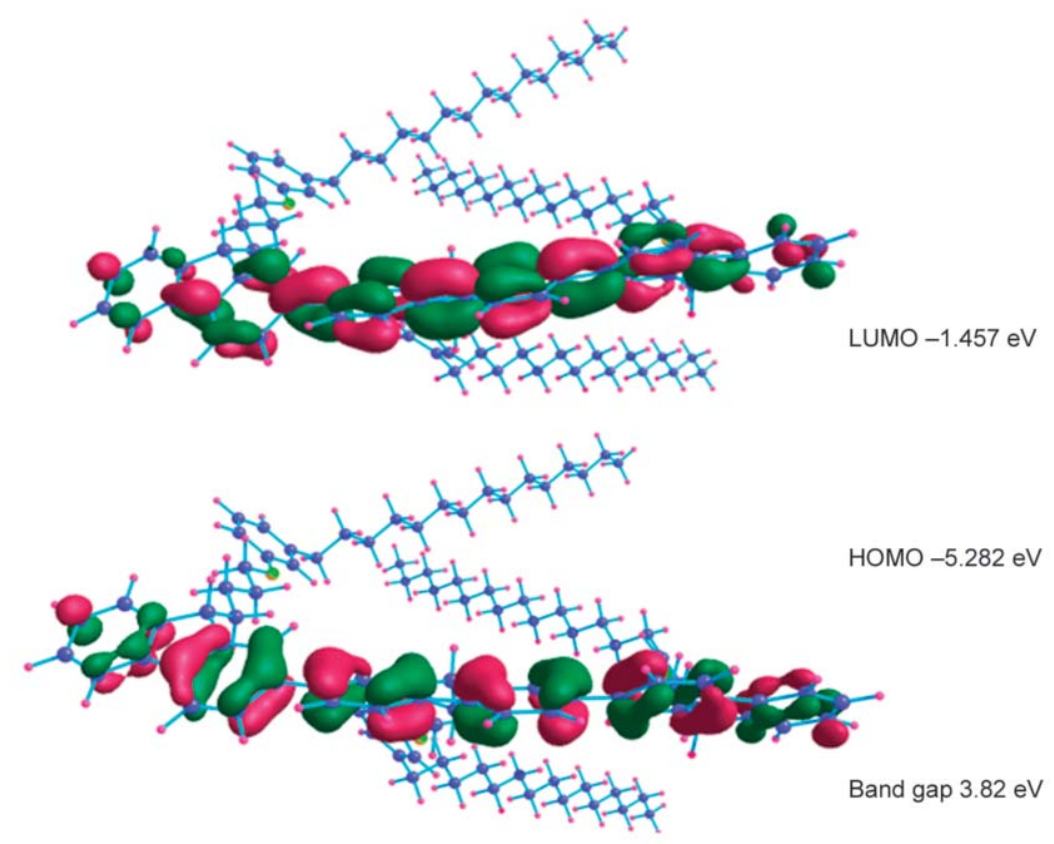

Figure 7. Energy minimized structure of dimer (B3LYP Method).

to dimension of the supramolecular bilayer of the molecular chains. The energy minimized structures of bilayered PFLPDB obtained by the optimization studies using Gaussian with B3LYP method using 3-21 g basis set.

\subsection{Thermal stability}

Thermal stability of PFLPDB was carried out at heating at a rate of $10^{\circ} \mathrm{C} \cdot \mathrm{min}^{-1}$ under nitrogen atmosphere as shown in Figure 10. TG of PFLPDB showed initial degradation around $110^{\circ} \mathrm{C}$ can be due to the

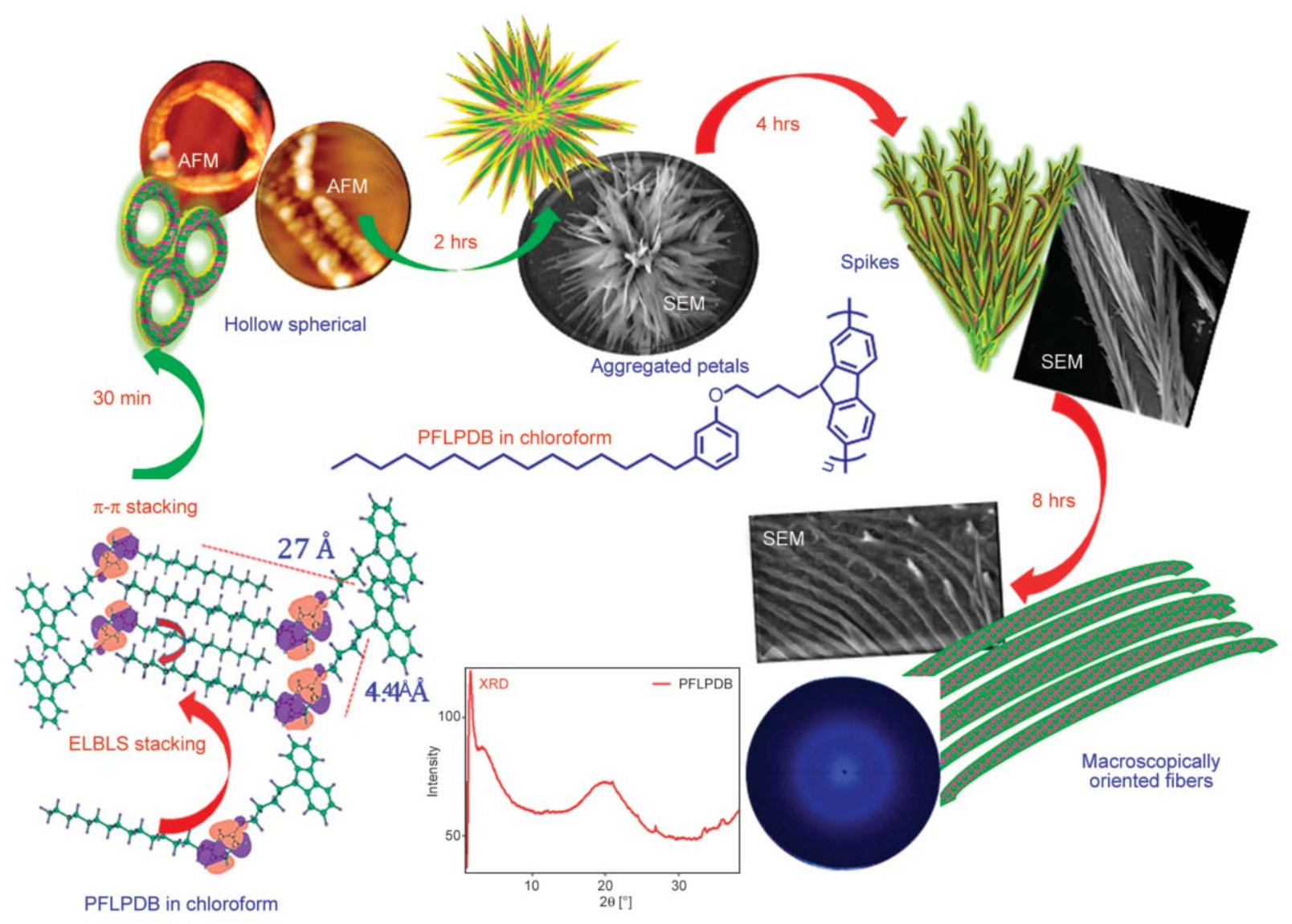

Figure 8. Self-assembly of PFLPDB in $\mathrm{CHCl}_{3}$. 


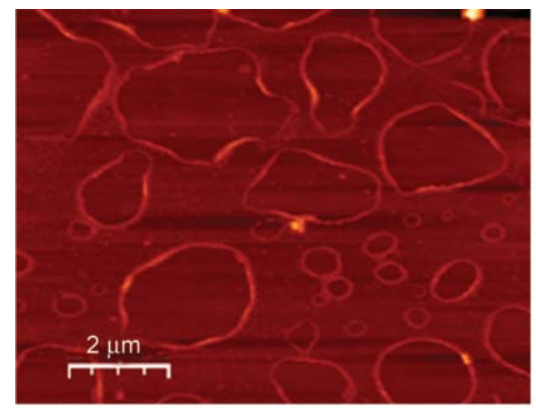

a)

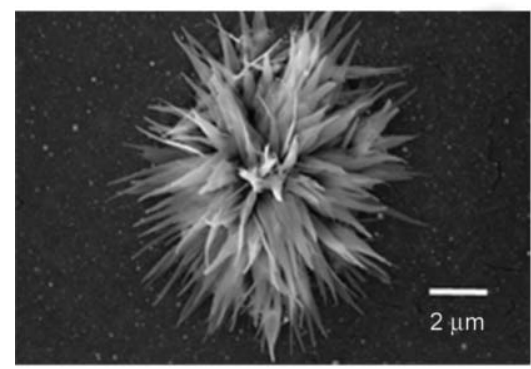

d)

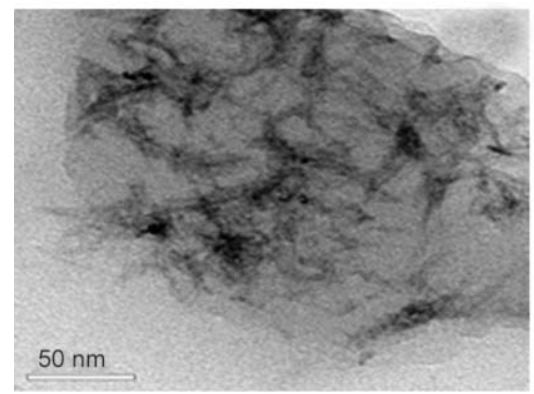

g)

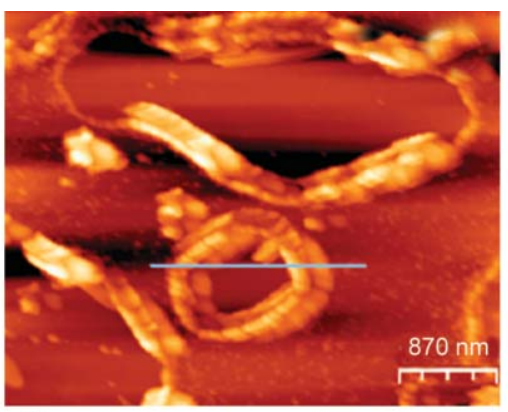

b)

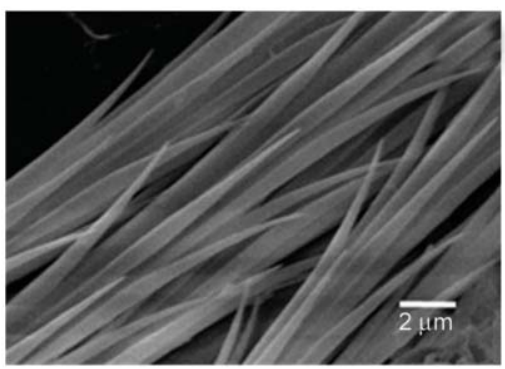

e)

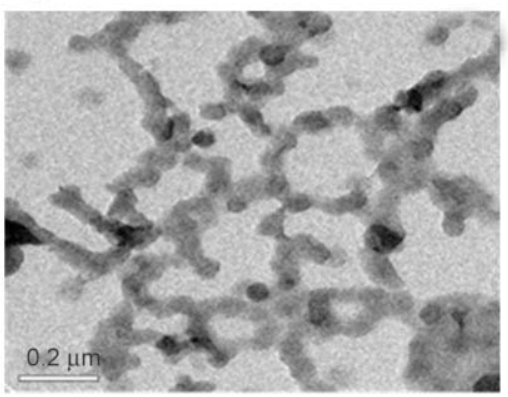

h)

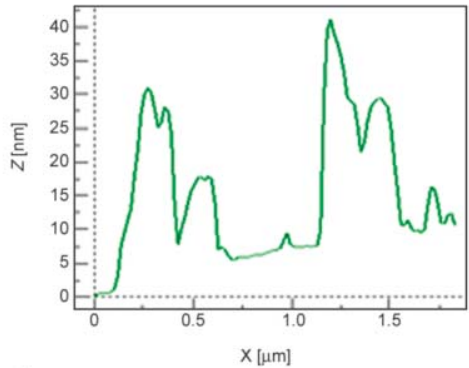

c)

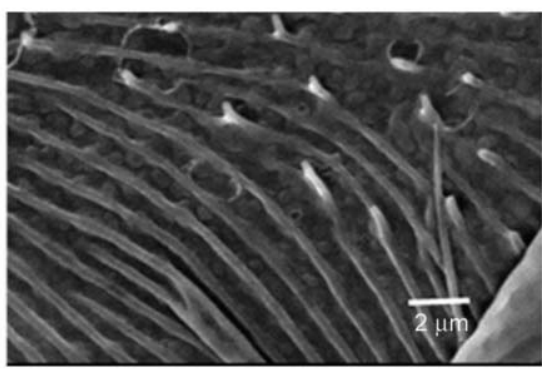

f)

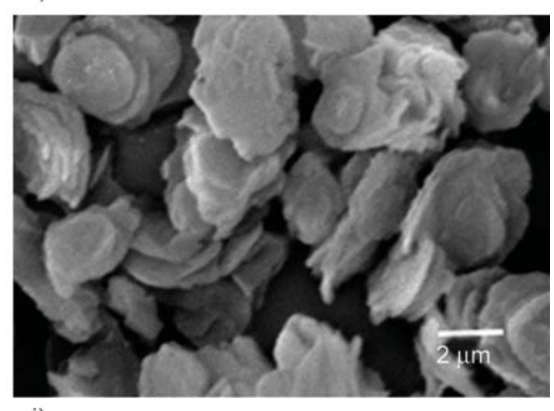

i)

Figure 9. AFM images of PFLPDB in $\mathrm{CHCl}_{3}$ a) after 30 minutes, b) $2 \mathrm{hr}$, c) height profile. SEM image of $\mathrm{PFLPDB} \mathrm{CHCl}_{3}$ after d) $2 \mathrm{hr}$, e) $4 \mathrm{hr}$, f) $8 \mathrm{hr}$, d) TEM images after g) $2 \mathrm{hr}$ and h) $8 \mathrm{hr}$, i) SEM image of PFLPDB in THF.

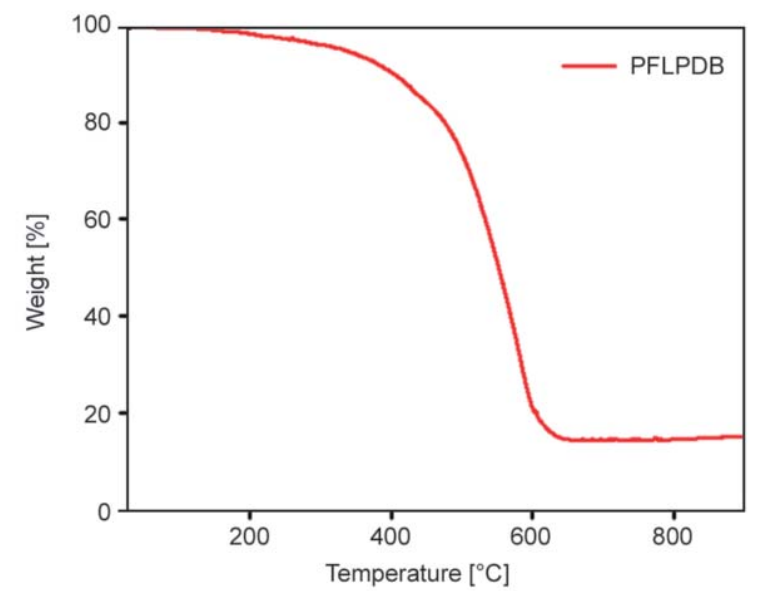

Figure 10. TGA curve of PFLPDB.

removal of moisture and other impurities. The second degradation was found to be $400^{\circ} \mathrm{C}$ contributed to the scission of the polymer backbone [38, 48].

\subsection{OFET device performance}

OFET device was fabricated with a configuration $\mathrm{Si} / \mathrm{SiO}_{2} / \mathrm{PFLPDB} / \mathrm{Ag}$ as shown in Figure 11a. Field effect charge transfer characteristics of the device OFET highly depedent on the orientation of polymer chain, grain size and the electronic states of the semiconducting molecules of the casted thin films [4954]. Films of PFLPDB in chloroform exhibited the formation of highly ordered macroscopic fibers without any grain boundary and measured electrical conductivity as $2.1 \cdot 10^{-2} \mathrm{~S} \cdot \mathrm{cm}^{-1}$ expected to be an excellent active material for the fabrication of OFET device. Active material PFLPDB prepared in chloroform solution ( $1 \mathrm{wt} \%$ PFLPDB) was casted on a silicon wafer substrate by spin coating. Later silver is thermally deposited on it which act as source and drain. $\mathrm{Si} / \mathrm{SiO}_{2}$ used as the gate electrode and gate insulator. Figure $11 \mathrm{~b}$ shows the transfer characteristics of gate voltage Vs drain current. When the gate voltage is varied from -20 to $15 \mathrm{~V}$, it has been observed that current started increase from $-0.2 \mathrm{~V}$ and showed maximum increase in drain current $10 \mathrm{~mA}$ at the gate voltage $-20 \mathrm{~V}$. It has been reported in the literature that when the gate electrode is biased negatively, the 

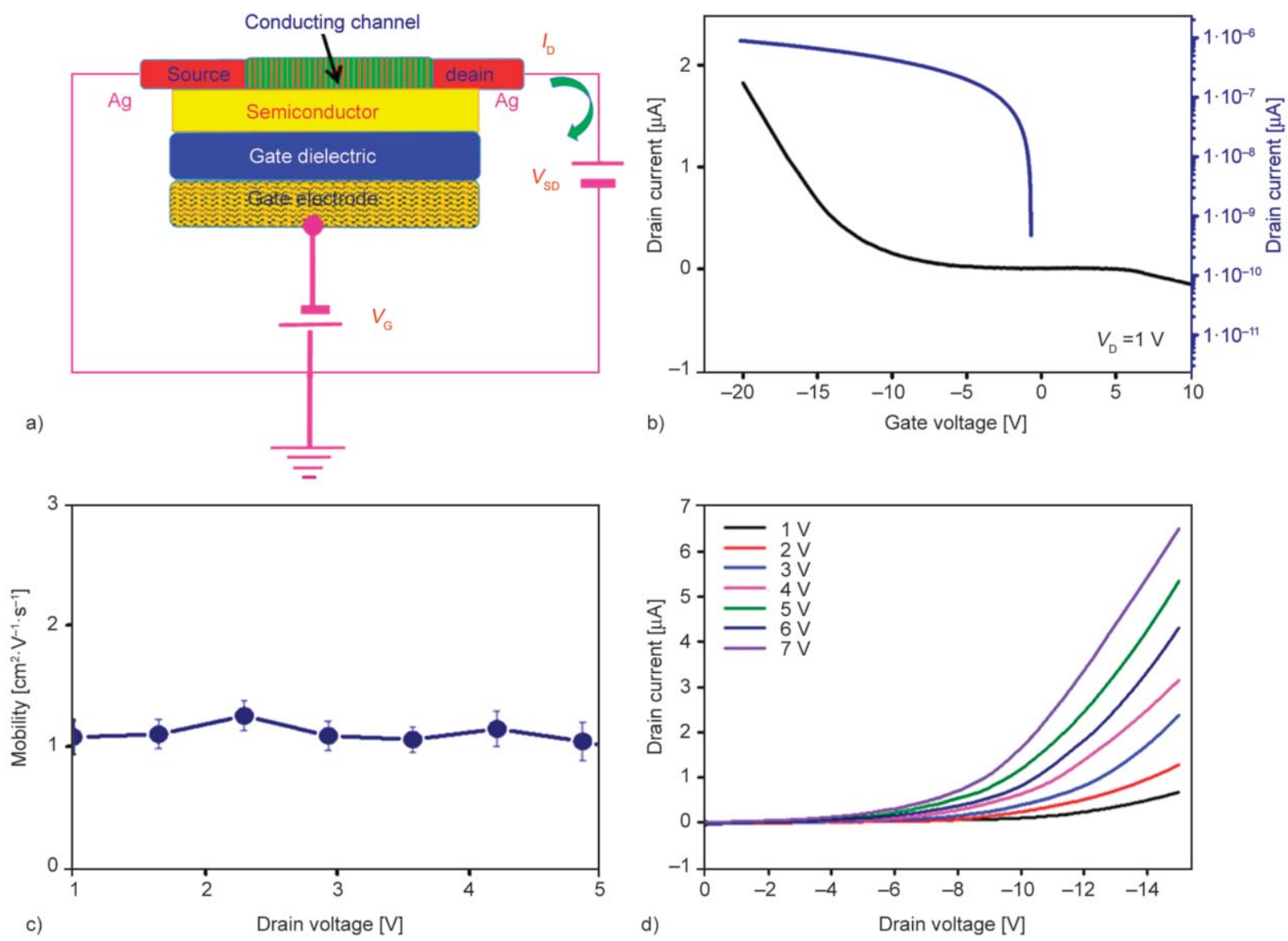

Figure 11. a) Schematic diagram for OFET device b) transfer characteristics c) variation of mobility with drain voltage (gate voltage $1 \mathrm{~V}$ ) d) out characteristics, d) as output characteristics.

transistor based on conducting polymer operates in the accumulation mode and holes are the major charge carriers in the transistor channel [55]. Field effect mobility of the transistors was calculated from the transfer characteristics using the Equation (4):

$\mu_{\mathrm{FE}}=\frac{L}{W C_{\mathrm{i}}} \frac{g_{\mathrm{m}}}{V_{\mathrm{D}}}$

where $L$ and $W$ are the length and thickness of the channel, $C_{\mathrm{i}}$ is the specific capacitance and $V_{\mathrm{D}}$ is the drain voltage. $g_{\mathrm{m}}$ is the trans conductance of the device derived from the linear part of transfer characteristics of the transistor as given in Equation (5):

$g_{\mathrm{m}}=\frac{\partial I_{\mathrm{D}}}{\partial V_{\mathrm{D}}}$

Field effect mobility of FLPDB based transistor showed incremental variation with the drain voltage Figure 11c, which may due to the formation of delocalised charge carriers without any trap filled with charge carriers as attributed to the macroscopically oriented fibers without any grain boundary. This is in sharp contrast to the conventional inorganic semiconductors that rely on band like transport [56].
During the hopping process, charges propagate preferentially along the stacking axis of molecules through their overlapping $\pi$-orbitals. It has been widely shown that the structural organization of molecules plays an important role in this process. Since the nanofiber is highly oriented without out any grain boundary expected to exhibit high charge transfer characteristic through interchain and experience unhindered charge transport pathways [57]. From the transfer characteristic curve, it has been observed that it exhibited Field effect mobility of $1.076 \mathrm{~cm}^{2} \cdot \mathrm{v}^{-1} \cdot \mathrm{s}^{-1}$ at $1 \mathrm{~V}$ with ON/OFF ratio observed as $1.82 \cdot 10^{3}$. Output characteristics of transistor is given in Figure 11d.

\section{Conclusions}

In summary, we have successfully designed and prepared processable fluorene based semiconducting polymer PFLPDB through side chain engineering using a low cost renewable resource derived molecule, 3-pentadecyl phenol. PFLPDB exhibited macroscopically oriented fibers with excellent electrical conductivity along with low optical and electrochemical band gap. OFET device fabricated using PFLDB as an active material showed p-type charge carriers 
with charge transfer mobility $1.076 \mathrm{~cm}^{2} \cdot \mathrm{v}^{-1} \cdot \mathrm{s}^{-1}$ at $1 \mathrm{~V}$ with $\mathrm{ON} / \mathrm{OFF}$ ratio observed as $1.82 \cdot 10^{3}$. All these excellent results suggested that the developed design strategy can be exploited for the preparation active material for the fabrication of other microelectronic device for high technological applications.

\section{Acknowledgements}

We thank CSIR-JRF for financial support. We would like to thank Dr. A. Ajayaghosh, Director CSIR- NIIST, for all facilities and for their constant support and encouragement. We are thankful to Dr. C. H. Suresh for theoretical calculations. We are also thankful to Mr. Kiran Mohan, Mrs. Soumya, Mr. Aswin Maheswar and Mr. Amal Raj R.B. for TEM, SEM, AFM and XRD analysis. We are also grateful for financial support ISRO-RESPOND program.

\section{References}

[1] Yi Z., Liu L., Wang L., Cen C., Chen X., Zhou Z., Ye X., Yi Y., Tang Y., Yi Y., Wu P.: Tunable dual-band perfect absorber consisting of periodic cross-cross monolayer graphene arrays. Results in Physics, 13, 102217-102223 (2019). https://doi.org/10.1016/j.rinp.2019.102217

[2] Xiong Z., Cao L.: High magnetic-dielectric tunability in Ni nanocrystals embedded $\mathrm{BaTiO}_{3}$ films. Journal of Alloys and Compounds, 785, 200-205 (2019). https://doi.org/10.1016/j.jallcom.2019.01.193

[3] Xiong Z., Cao L.: Tailoring morphology, enhancing magnetization and photocatalytic activity via $\mathrm{Cr}$ doping in $\mathrm{Bi}_{25} \mathrm{FeO}_{40}$. Journal of Alloys and Compounds, 773, 828-837 (2019). https://doi.org/10.1016/j.jallcom.2018.09.344

[4] Xiong Z., Cao L.: Nanostructure and optical property tuning between the graphitic-like $\mathrm{CN}_{\mathrm{x}}$ and fullerenelike $\beta-\mathrm{C}_{3} \mathrm{~N}_{4}$ via $\mathrm{Fe}$ doping and substrate temperature. Journal of Alloys and Compounds, 775, 100-108 (2019). https://doi.org/10.1016/j.jallcom.2018.10.077

[5] Yi Z., Lin H., Niu G., Chen X., Zhou Z., Ye X., Duan T., Yi Y., Tang Y., Yi Y.: Graphene-based tunable tripleband plasmonic perfect metamaterial absorber with good angle-polarization-tolerance. Results in Physics, 13, 102149-102154 (2019). https://doi.org/10.1016/j.rinp.2019.02.085

[6] Baker C. O., Huang X., Nelson W., Kaner R. B.: Polyaniline nanofibers: Broadening applications for conducting polymers. Chemical Society Reviews, 46, 1510 1525 (2017). https://doi.org/10.1039/C6CS00555A

[7] Kanibolotsky A. L., Perepichka I. F., Skabara P. J.: Starshaped $\pi$-conjugated oligomers and their applications in organic electronics and photonics. Chemical Society Reviews, 39, 2695-2728 (2010).

https://doi.org/10.1039/b918154g
[8] Das T. K., Prusty S.: Review on conducting polymers and their applications. Polymer-Plastics Technology and Engineering, 51, 1487-1500 (2012). https://doi.org/10.1080/03602559.2012.710697

[9] Fabretto M. V., Evans D. R., Mueller M., Zuber K., Hojati-Talemi P., Short R. D., Wallace G. G., Murphy P. J.: Polymeric material with metal-like conductivity for next generation organic electronic devices. Chemistry of Materials, 24, 3998-4003 (2012).

https://doi.org/10.1021/cm302899v

[10] Yoo J. E., Lee K. S., Garcia A., Tarver J., Gomez E. D., Baldwin K., Sun Y., Meng H., Nguyen T-Q., Loo Y-L.: Directly patternable, highly conducting polymers for broad applications in organic electronics. Proceedings of the National Academy of Sciences, 107, 5712-5717 (2010). https://doi.org/10.1073/pnas.0913879107

[11] Ghosh S., Maiyalagan T., Basu R. N.: Nanostructured conducting polymers for energy applications: Towards a sustainable platform. Nanoscale, 8, 6921-6947 (2016). https://doi.org/10.1039/C5NR08803H

[12] Perevedentsev A., Stavrinou P. N., Smith P., Bradley D. D. C.: Solution-crystallization and related phenomena in 9,9-dialkyl-fluorene polymers. II. Influence of sidechain structure. Journal of Polymer Science Part B: Polymer Physics, 53, 1492-1506 (2015). https://doi.org/10.1002/polb.23797

[13] D’Arcy J. M., Tran H. D., Tung V. C., Tucker-Schwartz A. K., Wong R. P., Yang Y., Kaner R. B.: Versatile solution for growing thin films of conducting polymers. Proceedings of the National Academy of Sciences, 107, 19673-19678 (2010). https://doi.org/10.1073/pnas.1008595107

[14] Bai W., Guan M., Shang X., Yao R., Lai N., Xu Y., Lin J.: Photophysical properties of poly(phenylene-co-fluorene) synthesized via solid-state oxidative coupling polymerization. Dyes and Pigments, 148, 359-367 (2018). https://doi.org/10.1016/j.dyepig.2017.09.041

[15] Neo W. T., Loo L. M., Song J., Wang X., Cho C. M., Chan H. S. O., Zong Y., Xu J.: Solution-processable blue-to-transmissive electrochromic benzotriazole-containing conjugated polymers. Polymer Chemistry, 4, 4663-4675 (2013). https://doi.org/10.1039/c3py00677h

[16] Mei J., Bao Z.: Side chain engineering in solutionprocessable conjugated polymers. Chemistry of Materials, 26, 604-615 (2014). https://doi.org/10.1021/cm4020805

[17] Chang D. W., Ko S-J., Kim G-H., Bae S-Y., Kim J. Y., Dai L., Baek J. B.: Molecular engineering of conjugated polymers for solar cells and field-effect transistors: Side-chain versus main-chain electron acceptors. Journal of Polymer Science Part A: Polymer Chemistry, 50, 271-279 (2012). https://doi.org/10.1002/pola.25026 
[18] Lei T., Wang J-Y., Pei J.: Roles of flexible chains in organic semiconducting materials. Chemistry of Materials, 26, 594-603 (2014).

https://doi.org/10.1021/cm4018776

[19] Watanabe S., Fujita T., Ribierre J-C., Takaishi K., Muto T., Adachi C., Uchiyama M., Aoyama T., Matsumoto M.: Microcrystallization of a solution-processable organic semiconductor in capillaries for high-performance ambipolar field-effect transistors. ACS Applied Materials and Interfaces, 8, 17574-17582 (2016).

https://doi.org/10.1021/acsami.5b12713

[20] Poriel C., Rault-Berthelo J.: Dihydroindenofluorene positional isomers. Accounts of Chemical Research, 51, 1818-1830 (2018).

https://doi.org/10.1021/acs.accounts.8b00210

[21] Ying L., Huang F., Bazan G. C.: Regioregular narrowbandgap-conjugated polymers for plastic electronics. Nature Communications, 8, 14047/1-14047/13 (2017). https://doi.org/10.1038/ncomms14047

[22] Xue Y., Xue Z., Zhang W., Zhang W., Chen S., Lin K., $\mathrm{Xu}$ J.: Effects on optoelectronic performances of EDOT end-capped oligomers and electrochromic polymers by varying thienothiophene cores. Journal of Electroanalytical Chemistry, 834, 150-160 (2019).

https://doi.org/10.1016/j.jelechem.2019.01.007

[23] Xue Y., Xue Z., Zhang W., Zhang W., Chen S., Lin K., $\mathrm{Xu}$ J.: Enhanced electrochromic performances of polythieno[3,2-b]thiophene with multicolor conversion via embedding EDOT segment. Polymer, 159, 150-156 (2018).

https://doi.org/10.1016/j.polymer.2018.11.018

[24] Zhang G., Zhao Y., Kang B., Park S., Ruan J., Lu H., Qiu L., Ding Y., Cho K.: Fused heptacyclic-based acceptor-donor-acceptor small molecules: $N$-substitution toward high-performance solution-processable field-effect transistors. Chemistry of Materials, 31, 2027-2035 (2019).

https://doi.org/10.1021/acs.chemmater.8b05054

[25] Zhao K., Khan H. U., Li R., Hu H., Amassian A.: Carrier transport enhancement in conjugated polymers through interfacial self-assembly of solution-state aggregates. ACS Applied Materials and Interfaces, 8, 19649-19657 (2016).

https://doi.org/10.1021/acsami.6b04508

[26] Smyslov R. Y., Tomilin F. N., Shchugoreva I. A., Nosova G. I., Zhukova E. V., Litvinova L. S., Yakimansky A. V., Kolesnikov I., Abramov I. G., Ovchinnikov S. G., Avramov P. V.: Synthesis and photophysical properties of copolyfluorenes for light-emitting applications: Spectroscopic experimental study and theoretical DFT consideration. Polymer, 168, 185-198 (2019).

https://doi.org/10.1016/j.polymer.2019.02.015

[27] Egbe D. A. M., Türk S., Rathgeber S., Kühnlenz F., Jadhav R., Wild A., Birckner E., Adam G., Pivrikas A., Cimrova V., Knör G., Sariciftci N. S., Hoppe H.: Anthracene based conjugated polymers: Correlation between $\pi-\pi$-stacking ability, photophysical properties, charge carrier mobility, and photovoltaic performance. Macromolecules, 43, 1261-1269 (2010).

https://doi.org/10.1021/ma902273s
[28] Wang F., Nakano K., Segawa H., Tajima K.: Phytol-derived alkyl side chains for $\pi$-conjugated semiconducting polymers. Chemistry of Materials, 31, 2097-2105 (2019).

https://doi.org/10.1021/acs.chemmater.8b05240

[29] Huang J., Chen Z., Yang J., Ju H., Zhang W., Yu G.: Semiconducting properties and geometry-directed selfassembly of heptacyclic anthradithiophene diimidebased polymers. Chemistry of Materials, 31, 25072515 (2019).

https://doi.org/10.1021/acs.chemmater.8b05353

[30] Fukuda M., Sawada K., Yoshino K.: Fusible conducting poly(9-alkylfluorene) and poly(9,9-dialkylfluorene) and their characteristics. Japanese Journal of Applied Physics, 28, L1433-L1435 (1989).

https://doi.org/10.1143/JJAP.28.L1433

[31] Islam S. N., Gogurla N., Giri D., Ray S. K., Patra S. K.: Highly emissive fluorene and thiophene based $\pi$-conjugated A-alt-B copolymers: Synthesis, characterization and electroluminescence properties. Journal of Luminescence, 208, 509-518 (2019).

https://doi.org/10.1016/j.jlumin.2019.01.031

[32] Tseng H-R., Phan H., Luo C., Wang M., Perez L. A., Patel S. N., Ying L., Kramer E. J., Nguyen T-Q., Bazan G. C., Heeger A. J.: High-mobility field-effect transistors fabricated with macroscopic aligned semiconducting polymers. Advanced Materials, 26, 2993-2998 (2014).

https://doi.org/10.1002/adma.201305084

[33] Sasi R., Sarojam S., Devaki S. J.: High performing biobased ionic liquid crystal electrolytes for supercapacitors. ACS Sustainable Chemistry and Engineering, 4, 3535-3543 (2016).

https://doi.org/10.1021/acssuschemeng.6b00585

[34] Sudha J. D., Reena V. L., Pavithran C.: Facile green strategy for micro/nano structured conducting polyanilineclay nanocomposite via template polymerization using amphiphilic dopant, 3-pentadecyl phenol 4-sulphonic acid. Journal of Polymer Science Part B: Polymer Physics, 45, 2664-2673 (2007). https://doi.org/10.1002/polb.21273

[35] Sudha J. D., Sasikala T. S.: Studies on the formation of self-assembled nano/microstructured polyaniline-clay nanocomposite (PANICN) using 3-pentadecyl phenyl phosphoric acid (PDPPA) as a novel intercalating agent cum dopant. Polymer, 48, 338-347 (2007).

https://doi.org/10.1016/j.polymer.2006.10.030

[36] Xie L-H., Yin C-R., Lai W-Y., Fan Q-L. Huang W.: Polyfluorene-based semiconductors combined with various periodic table elements for organic electronics. Progress in Polymer Science, 37, 1192-1264 (2012). https://doi.org/10.1016/j.progpolymsci.2012.02.003

[37] Kadu R. K., Thakur P. B., Patil V. R.: Photophysical properties of new fluorene-based conjugated polymers containing polyphenylene-substituted dendronized core. Polymer Bulletin, 76, 595-613 (2019). https://doi.org/10.1007/s00289-018-2401-3 
[38] Hayashi S., Inagi S., Fuchigami T.: Synthesis of 9-substituted fluorene copolymers via chemical and electrochemical polymer reaction and their optoelectronic properties. Macromolecules, 42, 3755-3760 (2009). https://doi.org/10.1021/ma900358x

[39] Chen P., Yang G., Liu T., Li T., Wang M., Huang W.: Optimization of opto-electronic property and device efficiency of polyfluorenes by tuning structure and morphology. Polymer International, 55, 473-490 (2006). https://doi.org/10.1002/pi.1970

[40] Inaoka S., Advincula R.: Synthesis and oxidative crosslinking of fluorene-containing polymers to form conjugated network polyfluorenes: Poly(fluoren-9,9-diyl-altalkan- $\alpha, \omega$-diyl). Macromolecules, 35, 2426-2428 (2002). https://doi.org/10.1021/ma011466k

[41] Ahmad S.: Organic semiconductors for device applications: Current trends and future prospects. Journal of Polymer Engineering, 34, 279-338 (2014). https://doi.org/10.1515/polyeng-2013-0267

[42] Allard S., Forster M., Souharce B., Thiem H., Scherf U.: Organic semiconductors for solution-processable fieldeffect transistors (OFETs). Angewandte Chemie International Edition, 47, 4070-4098 (2008). https://doi.org/10.1002/anie.200701920

[43] Newsome C. J., Carter J. C., Wilson R. J., Burroughes J. H.: A high performance solution processable organic semiconductor material for OTFT devices. in 'Proceedings of SPIE - The International Society for Optical Engineering, 8117', 811710 (1-6) (2011).

https://doi.org/10.1117/12.896166

[44] Bilici A., Kaya İ., Yıldırım M.: A comparative study of 9,9-bis(4-aminophenyl)fluorene polymers prepared by catalytic and non-catalytic oxidative polymerisation methods. European Polymer Journal, 47, 1005-1017 (2011).

https://doi.org/10.1016/j.eurpolymj.2011.02.019

[45] Hai T. A. P., Sugimoto R.: Synthesis and characterization of copolymers composed of 3-hexylthiophene and fluorene via chemical oxidation with $\mathrm{FeCl}_{3}$. Polymer Journal, 48, 1115-1121 (2016). https://doi.org/10.1038/pj.2016.90

[46] Hirai T., Sato M., Kido M., Nagae Y., Kaetsu K., Kiyoshima Y., Fujii S., Ohishi T., White K. L., Higaki Y., Teraoka Y., Nishibori M., Kamitani K., Hanada K., Sugiyama T., Sugimoto R., Saigo K., Kojio K., Takahara A.: X-ray absorption fine structure study on the role of solvent on polymerization of 3-hexylthiophene with solid $\mathrm{FeCl}_{3}$ particles. Journal of Polymer Science Part A: Polymer Chemistry, 53, 2075-2078 (2015). https://doi.org/10.1002/pola.27720

[47] Ma Y., Sheng Y., Tang C., Hong X., Chen S-C., Zhu D., Zheng Q.: Indenofluorene based water soluble conjugated oligomers for $\mathrm{Hg}^{2+}$ detection. Sensors and Actuators B: Chemical, 176, 132-140 (2013).

https://doi.org/10.1016/j.snb.2012.09.024
[48] Modak A., Maegawa Y., Goto Y., Inagaki S.: Synthesis of 9,9'-spirobifluorene-based conjugated microporous polymers by $\mathrm{FeCl}_{3}$-mediated polymerization. Polymer Chemistry, 7, 1290-1296 (2016). https://doi.org/10.1039/C5PY01900A

[49] Wang D., Yuan Y., Mardiyati Y., Bubeck C., Koynov K.: From single chains to aggregates, how conjugated polymers behave in dilute solutions. Macromolecules, 46, 6217-6224 (2013). https://doi.org/10.1021/ma4011523

[50] Lee W. H., Cho J. H., Cho K.: Control of mesoscale and nanoscale ordering of organic semiconductors at the gate dielectric/semiconductor interface for organic transistors. Journal of Materials Chemistry, 20, 2549-2561 (2010).

https://doi.org/10.1039/b924415h

[51] Tsao H. N., Müllen K.: Improving polymer transistor performance via morphology control. Chemical Society Reviews, 39, 2372-2386 (2010). https://doi.org/10.1039/b918151m

[52] Wang H., Xu Y., Yu X., Xing R., Liu J., Han Y.: Structure and morphology control in thin films of conjugated polymers for an improved charge transport. Polymers, 5, 1272-1324 (2013).

https://doi.org/10.3390/polym5041272

[53] Chen X. L., Lovinger A. J., Bao Z., Sapjeta J.: Morphological and transistor studies of organic molecular semiconductors with anisotropic electrical characteristics. Chemistry of Materials, 13, 1341-1348 (2001). https://doi.org/10.1021/cm0008563

[54] Dong H., Wang C., Hu W.: High performance organic semiconductors for field-effect transistors. Chemical Communications, 46, 5211-5222 (2010). https://doi.org/10.1039/c0cc00947d

[55] Ando S., Nishida J-I., Fujiwara E., Tada H., Inoue Y., Tokito S., Yamashita Y.: Novel $p$ - and $n$-type organic semiconductors with an anthracene unit. Chemistry of Materials, 17, 1261-1264 (2005). https://doi.org/10.1021/cm0478632

[56] Yi Z., Chen J., Cen C., Chen X., Zhou Z., Tang Y., Ye X., Xiao S., Luo W., Wu P.: Tunable graphene-based plasmonic perfect metamaterial absorber in the THz region. Micromachines, 10, 1-11 (2019).

https://doi.org/10.3390/mi10030194

[57] Romain M., Chevrier M., Bebiche S., MohammedBrahim T., Rault-Berthelot J., Jacques E., Poriel C.: The structure-property relationship study of electron-deficient dihydroindeno[2,1-b]fluorene derivatives for $n$ type organic field effect transistors. Journal of Materials Chemistry C, 3, 5742-5753 (2015). https://doi.org/10.1039/c5tc00355e 